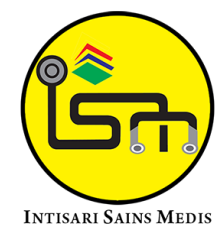

Published by Intisari Sains Medis

\section{Colonoscopy surveillance of colorectal cancer post-surgery in Sanglah General Hospital, Bali, Indonesia: a descriptive study}

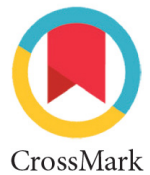

CrossMark
'Digestive Division, Department of Surgery, Faculty of Medicine, Universitas Udayana, Sanglah General Hospital, Bali, Indonesia
*Corresponding to:

Gede Eka Rusdi Antara; Digestive Division, Department of Surgery, Faculty of Medicine, Universitas Udayana, Sanglah General Hospital, Bali, Indonesia;

dr rusdi@yahoo.com

\section{Received: 2021-07-11}

Accepted: 2021-09-30

Published: 2021-10-18

\author{
Gede Eka Rusdi Antara ${ }^{1 *}$
}

\section{ABSTRACT}

Background: The postoperative surveillance of patients treated for colorectal cancer is intended to prolong survival by diagnosing recurrent and metachronous cancers at a curable stage as well as preventing metachronous cancer by detection and removal of precancerous polyps. This study evaluates the surveillance colonoscopy and its association with sociodemographic and clinical findings in a descriptive study.

Methods: This is a cross sectional study of colorectal cancer patients who underwent surveillance colonoscopy as follow up after tumor resection from January 2020 to September 2021 in Sanglah General Hospital. Clinical data were gathered from medical records and databases by a qualified reviewer. Data were analyzed descriptively using SPSS version 20 for

Windows.

Results: The majority of patients who underwent surveillance colonoscopy were male (82.40\%), tumor location at rectum (58.8\%), stage IV (29.40\%), underwent low anterior resection surgery (35.30\%) and received Folfox (35.30\%) or Capeox (35.30\%) adjuvant chemotherapy. There was 2 (11.80\%) residual mass found in this study. There was no significant difference between subjects who underwent surveillance colonoscopy with residual mass and without residual mass in all variables assessed ( $p>0.05$ ).

Conclusion: Colonoscopy surveillance plays an important role in early detection for any recurrence or pre-cancer lesion and metachronous cancer in a patient with colorectal malignancies in Sanglah General Hospital, Bali, Indonesia.

Keywords: Colonoscopy, Surveillance, Colorectal Cancer, Recurrent, Survival

Cite This Article: Antara, G.E.R. 2021. Colonoscopy surveillance of colorectal cancer post-surgery in Sanglah General Hospital, Bali, Indonesia: a descriptive study. Intisari Sains Medis 12(3): 732-734. D0I: 10.15562/ism.v12i3.1168

\section{INTRODUCTION}

Colorectal cancer is the third most common cancer in men and women. ${ }^{1}$ Despite a reduction in incidence and mortality over the past two decades from early detection and treatment, an estimated 137,000 new diagnoses and 50,000 deaths were expected in 2014 due to colorectal cancer. ${ }^{2}$ In addition, colorectal cancer is generally associated with a higher risk of local recurrence than cancer in other segments of the colon and requires additional considerations for surveillance. ${ }^{1,3}$

Patients who have surveillance colonoscopy following colorectal cancer resection have lower overall but not disease-specific mortality, according to observational studies using large administrative databases and meta- analysis of Randomized Controlled Trials (RCTs). ${ }^{4-8}$ The most significant outcome in cancer trials is cancer-specific mortality. ${ }^{9}$ Because recurrent adenocarcinoma of the colon and rectum can still be treated with acceptable 5-year survival rates, tumor surveillance plays an important role.

Early detection of recurrent disease from colorectal cancer allows for effective treatment with the intention of a cure. Colonoscopy within the first year after resection has its place in the surveillance due to a high rate of metachronous secondary tumors missed in the initial endoscopy. Once completed, it needs not be repeated for at least 3 years. ${ }^{10}$

Based on those mentioned above, this study aims to evaluate the colonoscopy surveillance of colorectal cancer postsurgery in Sanglah General Hospital, Bali, Indonesia, as a descriptive study.

\section{METHODS}

A cross-sectional study was conducted at Sanglah General Hospital, Bali, Indonesia, among patients with colorectal cancer that underwent colonoscopy surveillance as follow-up after tumor resection from January 2020 to September 2021. Patients will be deemed eligible as inclusion criteria enrolled in this study if they have undergone tumor resection due to colon cancer (up to $15 \mathrm{~cm}$ above the anal margin) and rectum (between the anal margin and $15 \mathrm{~cm}$ above it), where curative surgery by first time was applied in the setting of Sanglah General Hospital, Bali, Indonesia. Colorectal cancer diagnosis is based on anatomopathological diagnosis after a biopsy by colonoscopy. In addition, the exclusion criteria are colon or rectum 
in situ cancer, inoperable tumor, and terminal illness. Clinical data were gathered from medical records and databases by a qualified reviewer. Data were analyzed by using SPSS version 20 for Windows descriptively.

\section{RESULTS}

In this study, a total of 17 cases of surveillance colonoscopy after surgery and adjuvant chemotherapy will be further analyzed (Table 1). The total cases where residual mass was found were 2 out of 17 cases $(11.8 \%)$. The majority of patients who underwent surveillance colonoscopy were $61.53 \pm 9.88$ years old, male $(82.40 \%)$, tumor location at rectum $(58.80 \%)$, stage IV (29.40\%), underwent low anterior resection surgery $(35.30 \%)$ and received Folfox $(35.30 \%)$ or Capeox $(35.30 \%)$ adjuvant chemotherapy (Table 1). In 2 subjects with residual mass, they were aged $58.00 \pm 1.41$ years old, male, tumor location in the rectum (5.90\%) and descending colon $(5.90 \%)$, stage IIIB $(5.90 \%)$ or IIIC (5.90\%), showed no metastases $(11.80 \%)$, underwent hemicolectomy (5.90\%) or low anterior resection (5.90\%) and received Folfox (5.90\%) or Capeox (5.90\%) chemotherapy. There was no significant difference between subjects who underwent surveillance colonoscopy with residual mass and without residual mass in all variables assessed $(p>0.05)$ (Table 1).

Table 1. Characteristics of subjects who underwent surveillance colonoscopy with residual mass and without residual mass

\begin{tabular}{|c|c|c|c|c|c|c|c|}
\hline \multirow[t]{2}{*}{ Variables } & \multicolumn{3}{|c|}{$\begin{array}{l}\text { Without Residual Mass } \\
\qquad(\mathrm{N}=15)\end{array}$} & \multicolumn{3}{|c|}{$\begin{array}{l}\text { Residual Mass } \\
\qquad(\mathrm{N}=2)\end{array}$} & \multirow[t]{2}{*}{$\mathbf{p}$} \\
\hline & $\mathbf{N}$ & $\%$ & Mean \pm SD & $\mathbf{N}$ & $\%$ & Mean \pm SD & \\
\hline Age (Years) & & & $61.53 \pm 9.88$ & & & $58.00 \pm 1.41$ & 0.367 \\
\hline \multicolumn{8}{|l|}{ Gender $(\mathrm{N}=17)$} \\
\hline Female & 3 & 17.60 & & 0 & 0.00 & & 0.669 \\
\hline Male & 12 & 70.60 & & 2 & 11.80 & & \\
\hline \multicolumn{8}{|l|}{ Location $(\mathrm{N}=17)$} \\
\hline Ascending colon & 2 & 11.80 & & 0 & 0.00 & & 0.476 \\
\hline Transverse colon & 1 & 5.90 & & 0 & 0.00 & & \\
\hline Descending colon & 1 & 5.90 & & 1 & 5.90 & & \\
\hline Sigmoid colon & 2 & 11.80 & & 0 & 0.00 & & \\
\hline Rectum & 9 & 52.90 & & 1 & 5.90 & & \\
\hline \multicolumn{8}{|l|}{ Stage $(\mathrm{N}=17)$} \\
\hline IIA & 3 & 17.60 & & 0 & 0.00 & & 0.411 \\
\hline IIB & 2 & 11.80 & & 0 & 0.00 & & \\
\hline IIIA & 1 & 5.90 & & 0 & 0.00 & & \\
\hline IIIB & 3 & 17.60 & & 1 & 5.90 & & \\
\hline IIIC & 1 & 5.90 & & 1 & 5.90 & & \\
\hline IV & 5 & 29.40 & & 0 & 0.00 & & \\
\hline \multicolumn{8}{|l|}{ Metastasis $(\mathrm{N}=17)$} \\
\hline No & 10 & 58.80 & & 2 & 11.80 & & 0.485 \\
\hline Yes & 5 & 29.40 & & 0 & 0.00 & & \\
\hline \multicolumn{8}{|l|}{ Surgery $(\mathrm{N}=17)$} \\
\hline Miles procedure & 1 & 5.90 & & 0 & 0.00 & & 0.605 \\
\hline Ultra-low anterior resection & 3 & 17.60 & & 0 & 0.00 & & \\
\hline Low anterior resection & 5 & 29.40 & & 1 & 5.90 & & \\
\hline Anterior resection & 2 & 11.80 & & 0 & 0.00 & & \\
\hline Hemicolectomy & 4 & 23.50 & & 1 & 5.90 & & \\
\hline \multicolumn{8}{|l|}{ Adjuvant chemotherapy $(\mathrm{N}=17)$} \\
\hline Folfiri & 4 & 23.50 & & 0 & 0.00 & & 0.659 \\
\hline Folfox & 5 & 29.40 & & 1 & 5.90 & & \\
\hline Capeox & 5 & 29.40 & & 1 & 5.90 & & \\
\hline Capecitabine & 1 & 5.90 & & 0 & 0.00 & & \\
\hline
\end{tabular}




\section{DISCUSSION}

Even after their cancer treatment is finished, colorectal cancer survivors require ongoing preventive care. Colorectal cancer survivors are at risk for both local recurrences and second primary malignancies, therefore early detection of second colorectal cancers and local recurrences using surveillance colonoscopy may improve treatment options and reduce mortality. ${ }^{11}$ The American Cancer Society and U.S. Multi-Society Task Force on Colorectal Cancer recommended ongoing colorectal surveillance for people with colorectal cancer via colonoscopy at 1 year after surgery, repeat in the following 3 years and every 5 years after that. ${ }^{12}$

Although some research implies that the risk of metachronous cancer is elevated primarily in the proximal colon among older survivors, all colorectal segments are at greater risk. Thus, in colorectal cancer patients, postoperative colonoscopy surveillance is recommended for the long term, or until the benefit is exceeded by reduced life expectancy due to age or competing for comorbidity. ${ }^{13} \mathrm{An}$ important distinction is made between colon and rectal cancer because of the higher propensity for local recurrence.

According to the literature, the studies compiled for this review reported colon and rectal cancer separately. More than $80 \%$ of anastomotic recurrences involve patients with cancer of the rectum or distal colon. ${ }^{14}$ The local recurrence rate of rectal cancer depends on accurate preoperative staging, neoadjuvant chemoradiation for locally advanced disease, and surgical technique. Rectal cancer recurrence is decreased by total mesorectal excision in which the rectum and mesorectal fascia are resected by precise, sharp dissection. ${ }^{14}$

Sanglah General Hospital has a high rate of colorectal cancer admissions, but a low rate of surveillance colonoscopies. Education and regular follow-up may help to increase the rate of surveillance. Sociodemographic, educational, and financial factors can all have an impact on this. Colorectal surveillance systems and digital applications can be useful instruments for improving surveillance.

\section{CONCLUSION}

Colonoscopy surveillance plays an important role in early detection for any recurrence or pre-cancer lesion and metachronous cancer in a patient with colorectal malignancies. Early detection of any residive mass and the metachronous lesion will allow early treatment and affect the overall survival rate for colorectal cancer.

\section{ACKNOWLEDGMENTS}

The authors acknowledged the Division of Digestive Surgery, Department of Surgery, Sanglah General Hospital, Bali, Indonesia, which has supported this study.

\section{CONFLICT OF INTEREST}

There is no competing interest regarding the manuscript.

\section{ETHICS CONSIDERATION}

This study has obtained ethics approval from the Ethics Committee, Faculty of Medicine, Sanglah General Hospital, Bali, Indonesia prior to the study

\section{FUNDING STATEMENT}

This study was a self-funding study by the author listed in this study without grants, scholarships, or any other funding resources.

\section{AUTHOR CONTRIBUTION}

GERA is responsible for the study from the conceptual framework, data acquisition, data analysis until reporting the study results through publication.

\section{REFERENCES}

1. Kahi CJ, Boland CR, Dominitz JA, Giardiello FM, Johnson DA, Kaltenbach $\mathrm{T}$, et al. Colonoscopy Surveillance After Colorectal Cancer Resection: Recommendations of the US Multi-Society Task Force on Colorectal Cancer. Gastroenterology. 2016;150(3):758-768.e11.
2. Short MW, Layton MC, Teer BN, Domagalski JE. Colorectal cancer screening and surveillance. Am Fam Physician. 2015;91(2):93100.

3. Shaukat A, Kahi CJ, Burke CA, Rabeneck L, Sauer BG, Rex DK. ACG Clinical Guidelines: Colorectal Cancer Screening 2021. Am J Gastroenterol. 2021;116(3):458-479.

4. Fisher DA, Jeffreys A, Grambow SC, Provenzale D. Mortality and follow-up colonoscopy after colorectal cancer. Am J Gastroenterol. 2003;98(4):901-906.

5. Ramsey SD, Howlader N, Etzioni R, Brown ML, Warren JL, Newcomb P. Surveillance endoscopy does not improve survival for patients with local and regional stage colorectal cancer. Cancer. 2007;109(11):2222-2228.

6. Rulyak SJ, Lieberman DA, Wagner EH, Mandelson MT. Outcome of follow-up colon examination among a population-based cohort of colorectal cancer patients. Clin Gastroenterol Hepatol. 2007;5(4):470-407.

7. Tjandra JJ, Chan MK. Follow-up after curative resection of colorectal cancer: a metaanalysis. Dis Colon Rectum. 2007;50(11):17831799. doi:10.1007/s10350-007-9030-5

8. Pita-Fernández S, Alhayek-Aí M, GonzálezMartín C, López-Calviño B, Seoane-Pillado T, Pértega-Díaz S. Intensive follow-up strategies improve outcomes in nonmetastatic colorectal cancer patients after curative surgery: a systematic review and meta-analysis. Ann Oncol. 2015;26(4):644-656.

9. Black WC, Haggstrom DA, Welch HG. Allcause mortality in randomized trials of cancer screening. J Natl Cancer Inst. 2002;94(3):167173.

10. Vorburger SA, Gloor B, Candinas D. Tumor surveillance after resection of colorectal cancer. Ther Umsch. 2008;65(6):329-334.

11. Salz T, Weinberger M, Ayanian JZ, Brewer NT, Earle CC, Elston Lafata J, et al. Variation in use of surveillance colonoscopy among colorectal cancer survivors in the United States. BMC Health Serv Res. 2010;10:256.

12. Rex DK, Kahi CJ, Levin B, Smith RA, Bond JH, Brooks D, et al. Guidelines for colonoscopy surveillance after cancer resection: a consensus update by the American Cancer Society and the US Multi-Society Task Force on Colorectal Cancer. Gastroenterology. 2006;130(6):186571.

13. Liu L, Lemmens VE, De Hingh IH, de Vries E, Roukema JA, van Leerdam ME, et al. Second primary cancers in subsites of colon and rectum in patients with previous colorectal cancer. Dis Colon Rectum. 2013;56(2):158-68.

14. Kapiteijn E, Marijnen CA, Nagtegaal ID, Putter H, Steup WH, Wiggers T, et al. Preoperative radiotherapy combined with total mesorectal excision for resectable rectal cancer. N Engl J Med. 2001;345(9):638-46.

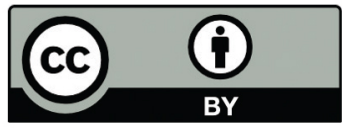

This work is licensed under a Creative Commons Attribution 